\title{
Mechanistic Studies on the Lipase-Catalyzed Ring-Opening Polymerization of Lactones
}

\author{
Hiroshi Uyama, Shuhei Namekawa, and Shiro Kobayash ${ }^{\dagger}$ \\ Department of Materials Chemistry, Graduate School of Engineering, \\ Tohoku University, Aoba, Sendai 980-77, Japan
}

(Received September 4, 1996)

\begin{abstract}
KEY WORDS Enzymatic Polymerization / Ring-Opening Polymerization / Michaelis-Menten Kinetics / Lactone / Macrolide /
\end{abstract}

Recently, polyester syntheses through enzymatic catalysis with various monomer combinations have been extensively investigated. ${ }^{1}$ By utilizing specific enzymatic catalysis, enantioselective ${ }^{2,3}$ and regioselective $e^{4}$ polymerizations have been developed. To obtain polymers of higher molecular weight in high yields, activated diesters having 2,2,2-trifluoroethyl, 2,2,2-trichloroethyl, or vinyl leaving groups have been often used as monomers for the enzymatic polycondensation. ${ }^{5,6}$

Enzymatic syntheses of aliphatic polyesters have also been achieved by ring-opening polymerization and copolymerization of lactones. ${ }^{7-16}$ Until now, small- (4membered) and medium-size lactones (6- and 7-membered) as well as macrolides (12-, 13-, and 16-membered lactones) were polymerized by lipase catalysts. In particular, these macrolides having much lower anionic polymerizability than $\varepsilon$-caprolactone $(\varepsilon-\mathrm{CL})$ exhibited unusually high reactivity through lipase catalysis. ${ }^{11,12,15}$ The lipase-catalyzed polymerization of the macrolides proceeded much faster than that of $\varepsilon-\mathrm{CL}$, which is the reversed tendency of chemical reactions such as an alkaline hydrolysis ${ }^{17}$ and anionic ring-opening polymerizations. ${ }^{18}$ To quantitatively evaluate the lipase-catalyzed polymerizability of these lactones, we made MichaelisMenten kinetics of the polymerization. ${ }^{19}$ This study is the first example to shed light on the mechanistic aspect via kinetics on the enzymatic ring-opening polymerization of lactones.

\section{EXPERIMENTAL}

\section{Materials}

$\varepsilon$-CL, 12-dodecanolide (DDL), and iso-propyl ether were stored over freshly activated type 4 molecular sieves. Pseudomonas fluorescens lipase (lipase PF) was donated by Amano Pharmaceutical Co. and used without further purification.

\section{Kinetic Study}

To a dried $50 \mathrm{~mL}$ flask was added $\varepsilon-\mathrm{CL}$ or DDL, 1-octanol $(0.039 \mathrm{~g}, 0.30 \mathrm{mmol})$, lipase PF $(200 \mathrm{mg})$, and iso-propyl ether $(10 \mathrm{~mL})$. The flask was kept at $60^{\circ} \mathrm{C}$ under gentle stirring. An aliquot $(10-20 \mu \mathrm{L})$ of the reaction mixture was removed every $1 \mathrm{~h}$ and subjected to gas chromatographic (GC) analysis for determination

\footnotetext{
$\dagger$ To whom correspondence should be addressed.
}

of the monomer conversion.

\section{Measurements}

GC analysis was carried out using a Shimadzu GC-14B apparatus equipped with an FID detector and a TC-5 column (GL Sciences). ${ }^{1} \mathrm{H}$ NMR spectra were recorded on a $400 \mathrm{MHz}$ Bruker DPX-400 spectrometer. Water content was measured using a Mitsubishi Kasei VA-06 Karl Fischer titrator.

\section{RESULTS AND DISCUSSION}

The enzymatic polymerization of lactones was carried out using lipase PF in iso-propyl ether at $60^{\circ} \mathrm{C}$. Monomers used in this study were $\varepsilon$-caprolactone (7membered, $\varepsilon$-CL) and 12-dodecanolide (13-membered, DDL). Lipase PF has high catalytic activity for these monomers. ${ }^{7,12}$ After $48 \mathrm{~h}$, the chloroform-soluble part of the reaction mixture from DDL monomer was analyzed by ${ }^{1} \mathrm{H}$ NMR spectroscopy. The product was found to be a mixture of the unreacted monomer and the corresponding oligomer. ${ }^{10} \mathrm{On}$ the basis of these data, we regarded the rate of the monomer consumption as the polymerization rate. In this study, the instantaneous monomer conversion was measured by gas chromatography (GC) for determination of the initial polymerization rate.

We propose that the lipase-catalyzed polymerization of lactones proceeds via "monomer-activated mechanism" and that the rate-determining step of the present over-all polymerization is the formation of the acyl-enzyme intermediate (Scheme 1). ${ }^{11}$ To ascertain the rate-determining step, polymerization was carried out in the absence and presence of 1-octanol in anhydrous iso-propyl ether. In the absence of the alcohol, a very small amount of water in the enzyme $(0.023 \mathrm{wt} \%$, de-

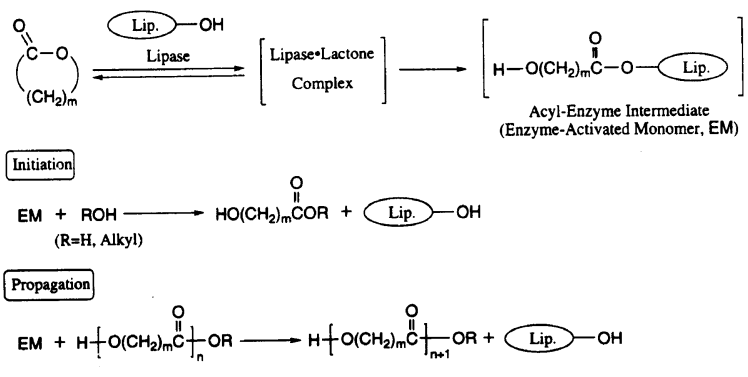

Scheme 1. 


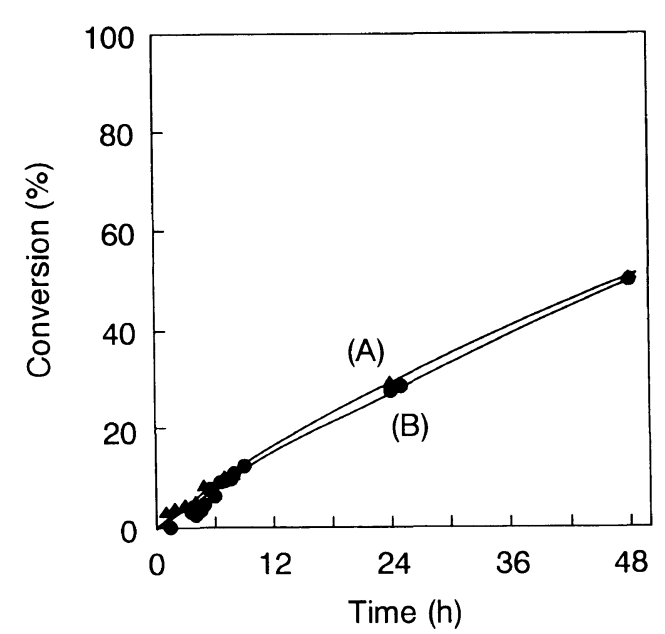

Figure 1. Time-conversion curves for the enzymatic polymerization of DDL $(0.5 \mathrm{M})$ in the (A) absence and (B) presence of 1-octanol $(0.03 \mathrm{M})$.

termined by Karl Fischer titration) acts as nucleophilic reagent to the acyl-enzyme intermediate in the initiation step, whereas in the presence of 1-octanol, it behaves as nucleophile in the initiation stage. ${ }^{10}$ Therefore, the concentration of the initiating species in the alcoholcontaining solvent is larger than that in the solvent without the alcohol. Figure 1 shows time-conversion curves in the polymerization of DDL in the absence and presence of $0.03 \mathrm{M} 1$-octanol. The monomer conversion value in the alcohol-containing solvent was almost the same as that in the absence of the alcohol, supporting the hypothesis that the formation of the acyl-enzyme intermediate is the rate-determining step in the present polymerization.

For kinetics of a two-substrate enzymatic reaction, there is the question as to which substrate is bound first. ${ }^{20}$ In the lipase-catalyzed polymerization of lactones in the presence of alcohol, the concentration of the hydroxyl group is considered to be constant in the early stage of the polymerization. Therefore, we paid attention to the stage of the acyl-enzyme intermediate formation and determined the kinetic parameters $K_{\text {m(lactone) }}$ and $V_{\max (\text { lactone) }}$ in the presence of an appropriate amount of 1-octanol.

Relationships between the monomer concentration and initial rate of monomer consumption are shown in Figure 2. The reaction rate increased with concentration of the lactone. At all monomer concentrations, the rate of DDL was larger than that of $\varepsilon$-CL, this agreeing with the enzymatic polymerization of both monomers in bulk. ${ }^{12}$

Figure 3 shows Hanes--Woolf plots ${ }^{20}$ in the enzymatic polymerization of lactones. The present polymerization followed Michaelis-Menten kinetics: linearity was observed for the both monomers in the Hanes-Woolf plot. The parameters obtained are summarized in Table I. Reciprocal of $K_{\mathrm{m} \text { (lactone) }}$ of DDL was about one-half as that of $\varepsilon-\mathrm{CL}$, on the other hand, $V_{\max (\text { lactone) }}$ of DDL was more than three times that of $\varepsilon-C L$, indicating that the larger polymerizability of DDL through lipase catalysis is mainly due to the larger reaction rate $\left(V_{\max }\right)$, but not to the binding abilities. These results suggest that the reaction process of the lipase-lactone complex to the

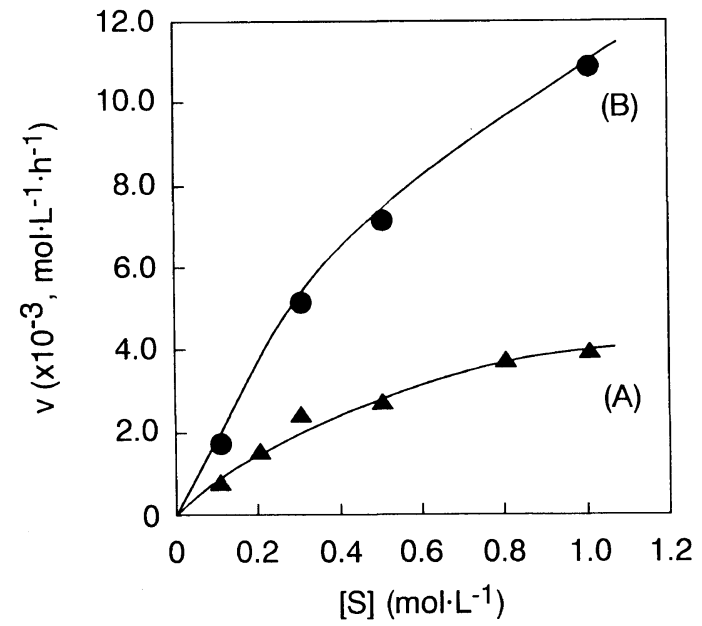

Figure 2. Relationship between monomer concentration and initial rate of monomer consumption: (A) $\varepsilon-C L$; (B) DDL.

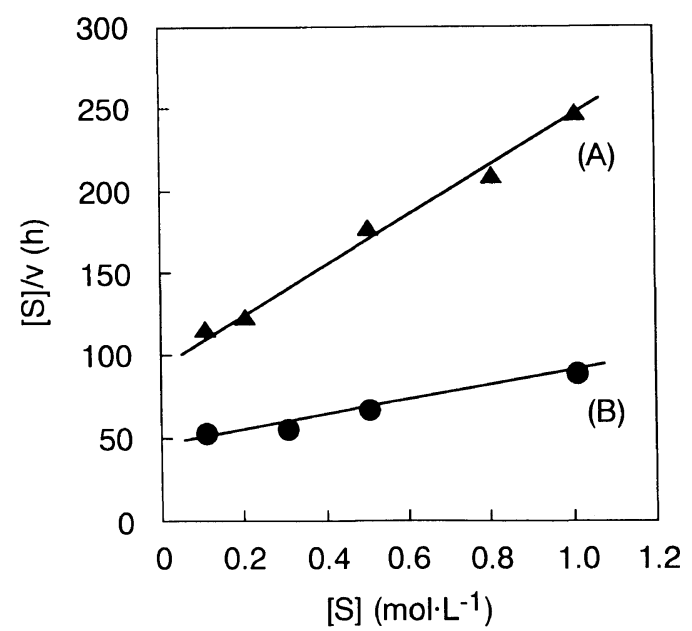

Figure 3. Hanes-Woolf plots in the enzymatic polymerization of lactones: (A) $\varepsilon$-CL; (B) DDL.

Table I. Michaelis-Menten kinetic parameters in ring-opening polymerization of lactones catalyzed by lipase $\mathbf{P F}^{\mathbf{a}}$

\begin{tabular}{cccc}
\hline \multirow{2}{*}{ Lactone } & $K_{\text {m(lactone) }}$ & & $V_{\max (\text { lactone) }}$ \\
\cline { 2 - 3 } & $\mathrm{mol} \mathrm{L}^{-1} \mathrm{~h}^{-1}$ & & $\times 10^{2}, \mathrm{~mol} \mathrm{~L}^{-1}$ \\
\hline D-CL & 0.61 & 0.66 \\
1.1 & 2.3 \\
\hline
\end{tabular}

${ }^{\text {a }}$ Polymerization was carried out using lipase PF $(200 \mathrm{mg})$ catalyst in the presence of 1 -octanol $(0.03 \mathrm{M})$ in iso-propyl ether $(10 \mathrm{~mL})$ at $60^{\circ} \mathrm{C}$.

acyl-enzyme intermediate is the key step in the present polymerization.

Michaelis-Menten kinetic parameters in the lipasecatalyzed ring-opening polymerization of lactones were determined. Difference of the polymerizability of lactones with different ring sizes is mainly due to the intracomplex reaction process, i.e., conversion of the lipase-lactone complex to the acyl-enzyme intermediate. Further investigation on the polymerization kinetics using various lactone monomers of different ring size is now under way in our laboratory. 
Acknowledgments. This work was partly supported by a Grant-in-Aid for Specially Promoted Research (No. 08102002) from the Ministry of Education, Science, and Culture of Japan and by Proposal Based Advanced Industrial Technology R\&D Program. We acknowledge the gift of lipase PF from Amano Pharmaceutical Co.

\section{REFERENCES}

1. S. Kobayashi, S. Shoda, and H. Uyama, Adv. Polym. Sci., 121, 1 (1995).

2. J. S. Wallace and C. J. Morrow, J. Polym. Sci., Polym. Chem. Ed., 27, 2553 (1989).

3. A. L. Margollin, J.-Y. Crenne, and A. M. Klibanov, Tetrahedron Lett., 28, 1607 (1987)

4. D. R. Patil, D. G. Rethwisch, and J. S. Dordick, Biotechnol. Bioeng., 37, 639 (1991).

5. E. M. Brazwell, D. Y. Filos, and C. J. Morrow, J. Polym. Sci., Polym. Chem. Ed., 33, 89 (1995).

6. H. Uyama and S. Kobayashi, Chem. Lett., 1687 (1994).

7. H. Uyama and S. Kobayashi, Chem. Lett., 1149 (1993).

8. H. Uyama, K. Takeya, and S. Kobayashi, Proc. Jpn. Acad., 69B, 203 (1993).

9. D. Knai, A. L. Gutman, and D. H. Kohn, J. Polym. Sci., Polym.
Chem. Ed., 31, 1221 (1993)

10. R. T. MacDonald, S. K. Pulapura, Y. Y. Svirkin, R. A. Gross, D. L. Kaplan, J. A. Akkara, G. Swift, and S. Wolk, Macromolecules, 28, 73 (1995).

11. H. Uyama, K. Takeya, and S. Kobayashi, Bull. Chem. Soc. Jpn., 68, 56 (1995).

12. H. Uyama, K. Takeya, N. Hoshi, and S. Kobayashi, Macromolecules, 28, 7046 (1995).

13. Y. Y. Svirkin, J. Xu, R. A. Gross, D. L. Kaplan, and G. Swift, Macromolecules, 29, 4591 (1996).

14. G. A. R. Nobes, R. J. Kazlauskas, and R. H. Marchessault, Macromolecules, 29, 4829 (1996).

15. H. Uyama, H. Kikuchi, K. Takeya, and S. Kobayashi, Acta Polymerica, 47, 357 (1996).

16. S. Namekawa, H. Uyama, and S. Kobayashi, Polym. J., 28, 730 (1996).

17. R. Huisgen and H. Ott, Tetrahedron, 6, 253 (1959).

18. R. Nomura, A. Ueno, and T. Endo, Macromolecules, 27, 620 (1994).

19. This study has been orally presented in parts: S. Namekawa, H. Uyama, and S. Kobayashi, Polym. Prepr., Jpn., 45, 199 (1996) H. Uyama and S. Kobayashi, Abstracts, "The 36th IUPAC International Symposium on Macromolecules," 1996, p 636.

20. A. Cornish-Bowden, "Principles of Enzyme Kinetics," Ed., Butterworth, Boston, 1976. 